\title{
Metagenomic profiles of free-living archaea, bacteria and small eukaryotes in coastal areas of Sichang island, Thailand
}

\author{
Naraporn Somboonna ${ }^{1 *}$, Anunchai Assawamakin², Alisa Wilantho², Sithichoke Tangphatsornruang², \\ Sissades Tongsima ${ }^{2}$
}

From Asia Pacific Bioinformatics Network (APBioNet) Eleventh International Conference on Bioinformatics (InCoB2012)

Bangkok, Thailand. 3-5 October 2012

\begin{abstract}
Background: Tha Wang and Tham Phang coasts, though situated at similar oceanographic positions on Sichang island, Chonburi province, Thailand, are different in bay geography and amount of municipal disturbances. These affect the marine ecosystems. The study used metagenomics combined with 165 and 185 rDNA pyrosequencing to identify types and distributions of archaea, bacteria, fungi and small eukaryotes of sizes ranges 0.45 and $\sim 30 \mu \mathrm{m}$.

Results: Following the open bay geography and minimal municipal sewages, Tham Phang coast showed the cleaner water properties, described by color, salinity, pH, conductivity and percent dissolved oxygen. The 16S and $18 \mathrm{~S}$ rDNA metagenomic profiles for Tha Wang and Tham Phang coasts revealed many differences, highlighting by Iow Lennon and Yue \& Clayton theta similarity indices (66.03-73.03\% for $16 \mathrm{~S}$ rDNA profiles, $2.85-25.38 \%$ for $18 \mathrm{~S}$ rDNA profiles). For $16 \mathrm{~S}$ rDNA, the percent compositions of species belonging to Proteobacteria, Bacteroidetes, Cyanobacteria, Firmicutes, Verrucomicrobia, Gammatimonadetes, Tenericutes, Acidobacteria, Spirochaetes, Chlamydiae, Euryarchaeota, Nitrospirae, Planctomycetes, Thermotogae and Aquificae were higher or distinctly present in Tha Wang. In Tham Phang, except Actinobacteria, the fewer number of prokaryotic species existed. For 185 rDNA, fungi represented $74.745 \%$ of the species in Tha Wang, whereas only $6.728 \%$ in Tham Phang. Basidiomycota (71.157\%) and Ascomycota (3.060\%) were the major phyla in Tha Wang. Indeed, Tha Wang-to-Tham Phang percent composition ratios for fungi Basidiomycota and Chytridiomycota were 1264.701 and 25.422, respectively. In Tham Phang, Brachiopoda (lamp shells) and Mollusca (snails) accounted for $80.380 \%$ of the 185 rDNA species detected, and their proportions were approximately tenfold greater than those in Tha Wang. Overall, coastal Tham Phang comprised abundant animal species.

Conclusions: Tha Wang contained numerous archaea, bacteria and fungi, many of which could synthesize useful biotechnology gas and enzymes that could also function in high-saline and high-temperature conditions. Tham Phang contained less abundant archaea, bacteria and fungi, and the majority of the extracted metagenomes belonged to animal kingdom. Many microorganisms in Tham Phang were essential for nutrient-recycling and pharmaceuticals, for instances, Streptomyces, Pennicilium and Saccharomyces. Together, the study provided metagenomic profiles of free-living prokaryotes and eukaryotes in coastal areas of Sichang island.
\end{abstract}

\footnotetext{
* Correspondence: Naraporn.S@chula.ac.th

'Department of Microbiology, Faculty of Science, Chulalongkorn University,

Bangkok 10330, Thailand

Full list of author information is available at the end of the article
}

\section{Biomed Central}

(c) 2012 Somboonna et al.; licensee BioMed Central Ltd. This is an open access article distributed under the terms of the Creative Commons Attribution License (http://creativecommons.org/licenses/by/2.0), which permits unrestricted use, distribution, and reproduction in any medium, provided the original work is properly cited. 


\section{Background}

Thailand situates around an equator, between 23.5 degree north and 23.5 degree south, causing the climate to be hot and rainy, which enhances the biodiversity of microorganisms. In addition to factors by sunlight, wind and tidal ranges, coastal niche represents areas where human disturbances are most situated, and is where land and sea meet with high influences by the bay characteristics. All these factors could affect types and distribution patterns of aquatic microorganisms and organisms [1-4]. Indeed, previous studies reported different proportions of organisms between Tha Wang and Tham Phang coasts of Sichang island, Thailand, and suggested the differences involved their differences in coastal quality (S. Piyatiratitivorakul and S. Rungsupa, personal communications). Nevertheless, no cultureindependent study for inclusive databases on free-living microorganisms had been conducted in Tha Wang and Tham Phang coasts of Sichang.

Sichang island, or Koh Sichang, Chonburi province, Thailand, represents one potential place for massively diversified microbial biodiversity. Sichang island was originally a royal palace for King Rama IV-VI, and has been a gateway for local and international cargo transportation since 1800s. Nowadays, Sichang island serves as a historical sites for visitors, pier for merchants and related industries, and place for residents with assorted human-related activities, all of which affect water quality, aquatic species diversity and species richness in Sichang coastal water. The east and the west coasts of Sichang island pose the uniqueness in the bay geographies. Locating on the east named Tha Wang has comparatively close water circulation due to its closeness to two other islands, Khaam Yai and Prong islands, and the mainland of Chonburi province (Figure 1). Tha Wang is populated with residents, residential houses, piers, topioca starch agriculture, and shipping and fishing industries. In contrast, locating on the west named Tham Phang, also called collapsed cave beach, has more open water circulation (Figure 1). Tham Phang is minimally populated by islanders except occasional visitors, and has neither agriculture nor industry. Subsequently, more and increasing amount of wastes was reported in Tha Wang but Tham Phang beach. These included glass bottles, plastics, biodegradable garbage, metals and hazardous materials (S. Rungsupa, personal communication) [5]. More abundant and species-diverse of crabs were reported on Tha Wang (Shannon's diversity index $=0.895$, Margalef's species-richness index $=4.346$ ) than Tham Phang beaches (Shannon's diversity index = 0.141, Margalef's species-richness index $=0.991$ ) because of the more deposition of organic matters from Tha Wang's wastes that could serve as food sources for the crabs (S. Piyatiratitivorakul and S. Rungsupa, personal communications and unpublished data).
Presently, $<1 \%$ of microbiota has been discovered, primarily owning to the limited cultivation ability and limited NCBI databases [6,7]. Culture-independent approach was first proposed by Norman R. Pace and colleagues [6]. Global ocean sampling exploration (GOS) was launched in 2003 by Craig Venter to gain understanding of prokaryotic genomes and diversity for whole marine environments, including coastal water, open ocean, seafloor and seawater at different depths, starting from Sargasso Sea to West Coasts and open oceans of the United States, Baltic, Mediterranean, and Black Seas, for examples $[1,3,4,8,9]$. Indeed, ocean accounts for approximately $360,000,000 \mathrm{~m}^{2}(\sim 71 \%)$ of the earth surface, and serves as the largest bioproductive resources. Consequently, tremendously new species of bacteria have been discovered, and much information on microbial biodiversity in marine ecosystems has been unveiled by metagenomics.

This study used metagenomics combined with $16 \mathrm{~S}$ and $18 \mathrm{~S}$ ribosomal DNA sequencing, and represented the first to identify the biodiversity of free-living archaea, bacteria and small eukaryotes in coastal areas of Sichang island. Each sample site comprised three independent seafloor and seawater sample collections as guided by SMaRT scientists to most represent the overall sampling collections of each coastal area; besides, these two coastal areas are not that vast. Different prokaryotic and eukaryotic species and their species distributions in Tha Wang and Tham Phang coastal water were analyzed in associated with their differential characteristics in the bay geographies and manmade activities. Our prokaryotic databases were also compared against various GOS databases to better understand the ecosystem of Sichang coasts, and obtain the comprehensive picture of the entire marine ecosystems. Hopefully, our study helps enhance knowledge on the global marine ecosystems, supporting the GOS exploration.

\section{Results}

\section{Different coastal characteristics of Sichang island}

Additional File 1 described general water properties of Tha Wang and Tham Phang. The water temperatures were roughly equal as the two sites are only $0.010^{\circ}$ latitude and $0.012^{\circ}$ longitude apart. The minor increase in water temperature of $0.7^{\circ} \mathrm{C}$ in Tham Phang was likely because of an atmosphere temperature that arose in the afternoon as the Tham Phang water sampling was conducted after the Tha Wang water sampling. Supportively, the monthly temperature for Tha Wang and Tham Phang coastal waters in February, 2010, as measured by Sichang Marine Science Research and Training Station (SMaRT; Chulalongkorn University, Thailand) were both $30^{\circ} \mathrm{C}$. Average yearly temperature of Tha Wang and Tham Phang coasts for the year 2010 were 29.55 and $29.48^{\circ} \mathrm{C}$ (S. Rungsupa, personal communication and unpublished data). 


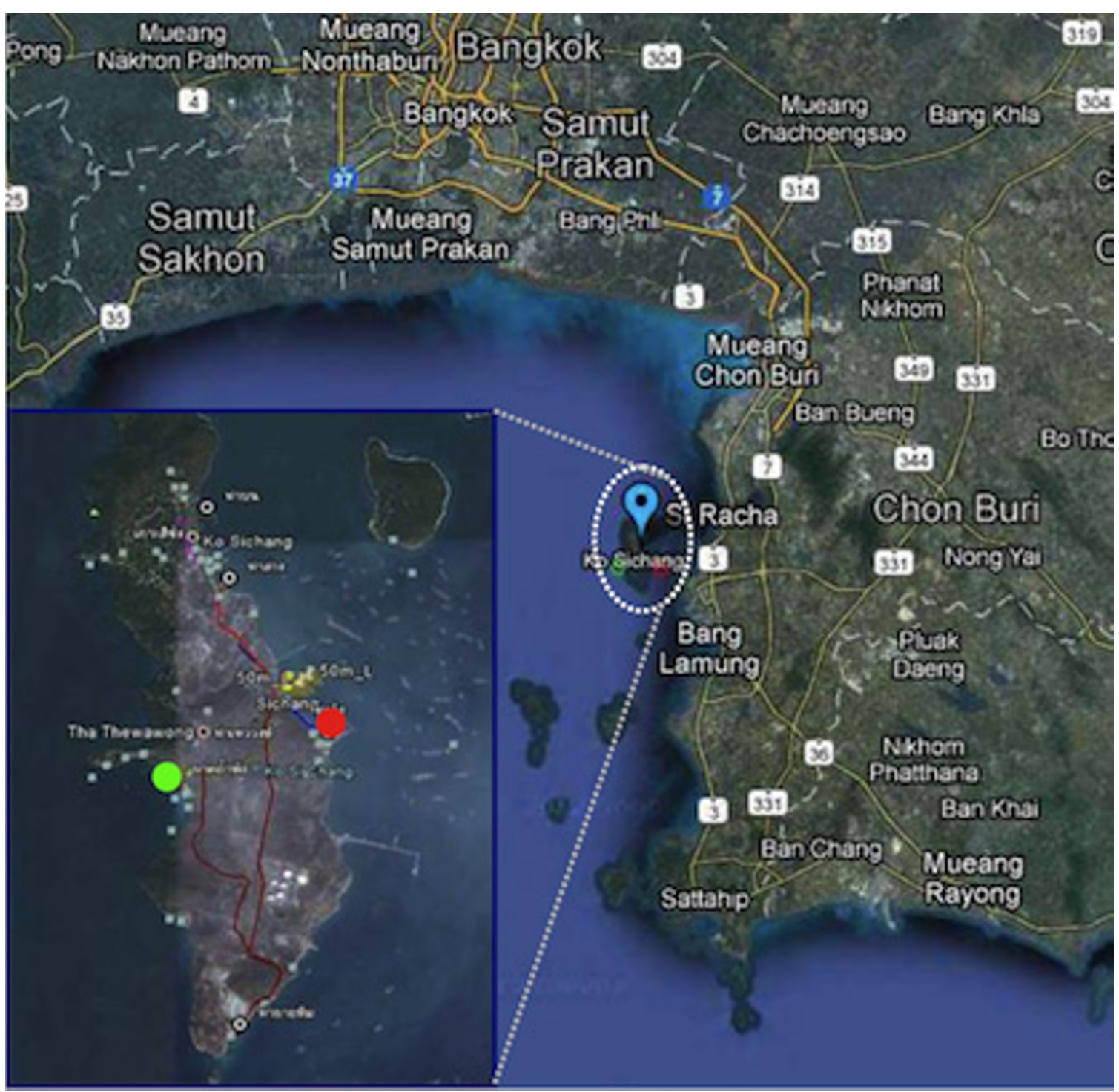

Figure 1 Satellite map of Tha Wang and Tham Phang coasts, Sichang island. Pictures were from Google Satellite Maps, retrieved on 26 April 2012, from http://www.mapandia.com/thailand/central/chon-buri/ko-si-chang/. Blue represents central of Sichang island. On the lower left corner was a zoon-in picture of Sichang island. Red and green circles represent Tha Wang and Tham Phang sampling sites.

However, compared with Tham Phang, Tha Wang coast had more opaque water color, less salinity and $\mathrm{pH}$, and high conductivity (Additional File 1). These differences, together with the facts that Tha Wang coast possess burdens by the relatively close bay geography and the growing residents and industries, suggested the differences in the microbial biodiversity was possible.

\section{Metagenomic DNA isolation of Tha Wang and Tham Phang coasts}

Particles and organisms of larger than $\sim 30$ micron in diameter size were prohibited by the primary filtration using 4-layer sterile cheesecloth. The 4-layer cheesecloth was measured the gap size to be $30 \mu \mathrm{m}$ in average (unpublished data). By passing the primary-filtrated water through a 0.45 -micron sterile filter paper, the microorganisms of sizes ranges 0.45 to $30 \mu \mathrm{m}$ were collected and their total genomes were isolated. Triplicate water sampling and independently triplicate metagenomic DNA extraction experiments were performed per site; the metagenomic DNA concentrations for Tha Wang and Tham Phang were 0.50 and $0.40 \mathrm{ng} / \mathrm{ml}$ of seawater, respectively (Additional file 2).

\section{Prokaryotic diversity of Tha Wang and Tham Phang coasts}

Libraries of Tha Wang and Tham Phang-tagged 16S rDNA sequences were successfully constructed and sequenced. Of 29,739 reads, 3,541 reads (11.91\%) were 
initially removed from an analysis as they were $<100$ bases in length, leaving 17,404 reads for Tha Wang and 8,794 reads for Tham Phang. All the reads have base length within accepted read lengths by the 454 GS/FLX sequencer, and the median read length was 404 bases. With default thresholds by VITCOMIC (E-value $\leq 1 \mathrm{E}-08$,

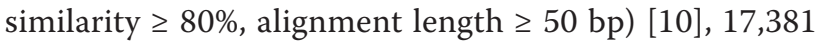
reads for Tha Wang and 8,763 reads for Tham Phang had sequence homologies to nucleotide sequences in NCBI non-redundant database $[10,11]$. Additional 6 reads for Tha Wang (Proteobacteria 6 reads, Actinobacteria 2 reads, Chloroflexi 1 read) and none for Tham Phang were identified using 1E-08 < E-value $\leq 1 \mathrm{E}-02.17$ reads for Tha Wang $(0.098 \%)$ and 31 reads for Tham Phang $(0.353 \%)$ remained unidentified $16 \mathrm{~S} \mathrm{rDNA}$ reads due to non-significant E-values.

Species diversity and relative species abundance of the identifiable reads were displayed in Additional files 3: A and B. RDP [8,12] and Greengenes [13] databases were included to generate the broader databases for species annotation, and the results were similar to Additional files 3: A and B (unpublished data). Whilst the two coasts shared many natural species and pattern of species distribution, more diversified prokaryotic species were denoted in Tha Wang (Figure 2, and Additional file 3: C). Meanwhile phylum Proteobacteria was dominant in both areas, many other phyla, including Bacteroidetes, Cyanobacteria, Firmicutes, Verrucomicrobia, Gammatimonadetes, Tenericutes, Acidobacteria, Spirochaetes and Chlamydiae were enriched in coastal water of Tha Wang than Tham Phang (Figure 3). Phyla Euryarchaeota, Planctomycetes, Nitrospirae, Chlorobi, Thermotogae and Aquificae were present only in Tha Wang coast (Figure 3). Examples of free-living prokaryotic species specific to Tha Wang coast were Thermodesulfovibrio yellowstonii, Herpetosiphon aurantiacus, Petrotoga mobilis, Thermotoga neapolitana, Thermotoga petrophila, Halothermothrix orenii, Microcystis aeruginosa, Rhodopirellula baltica, Aquifex aeolicus, Methanopyrus kandleri, Methanococcus aeolicus, Methanoculleus marisnigri, Methanocorpusculum labreanum, Methanothermobacter thermautotrophicus and Aster yellows (Additional file 3: C). For Tham Phang, species in fewer phyla were denoted (Figure 2), and phyla Actinobacteria and DeinococcusThermus were present at the higher proportion than Tha Wang (Figure 3). Lennon and Yue \& Clayton theta similarity indices indicated 66.03-73.03\% of similarity (Lennon index 0.7303, Yue \& Clayton theta 0.6603) among prokaryotic communities between Tha Wang and Tham Phang coasts.

\section{Eukaryotic diversity of Tha Wang and Tham Phang coasts}

Libraries of Tha Wang and Tham Phang-tagged 18S rDNA sequences were successfully constructed and sequenced. Of 109,024 reads, 6,698 reads (6.14\%) were removed as they were $<100$ bases in length, leaving 102,326 reads (Tha Wang 5,858 reads, Tham Phang 96,468 reads) for the analysis. All the reads have base length within accepted read lengths by the 454 GS/FLX sequencer, and the median read length was 465 bases. All the sequences were compared with NCBI non-redundant [11], EMBL [14,15] and SILVA [16] databases using BLASTN [10]. With default VITCOMIC parameters, 2,831 reads of Tha Wang and 95,961 reads of Tham Phang had homologous $18 \mathrm{~S}$ rDNA sequences. Additional 12 and 15 reads for Tha Wang (Apicomplexa 1 read, Streptophyta 1 read, Dinophyta 9 reads, Porifera 1 read) and Tham Phang (Platyhelminthes 3 reads, Rotifera 1 read, Arthropoda 4 reads, Porifera 6 reads, Chlorophyta 1 read) were identified when the E-value was adjusted to $1 \mathrm{E}$ $08<$ E-value $\leq 1 \mathrm{E}-02$. The number of unidentified $18 \mathrm{~S}$ rDNA reads, representing novel species, due to non-significant E-values by BLASTN, remained high for Tha Wang (3,015 reads, accounting for $51.468 \%$ of 5,858 reads) but Tham Phang (492 reads, $0.051 \%$ of 96,468 reads). These unidentified reads were excluded from the analysis.

Species diversity of the identified $18 \mathrm{~S}$ rDNA reads were displayed in Additional files 3: D and E. Unlike the prokaryotic communities, the free-living eukaryotic communities between the two coasts shared fewer similarities and more diverse species and phyla distribution pattern (Figure 4, and Additional file 3: F), highlighting by low Lennon (0.2538) and Yue \& Clayton theta (0.0285) similarity indices.

While phyla Basidiomycota and Ascomycota were predominant in Tha Wang, other kingdoms of lives and species compositions were found common in Tham Phang (Figure 5). For Tha Wang, fungi were the major kingdom (74.745\%), followed by kingdoms of animals (14.246\%), protists $(8.407 \%)$ and plants $(2.603 \%)$. Tha Wang-to-Tham Phang percent composition ratios for fungi Basidiomycota, animals Tardigrada, fungi Chytridiomycota, plants Cryptophyta and protists Dinophyta were 1264.701, 33.759, 25.422, 16.879 and 13.580, respectively (Figure 5). Examples of aquatic $18 \mathrm{~S}$ rDNA species specific for Tha Wang were Dictyostelium deminutrivum, Penicillium oblatum, Pugettia quadridens and Sphyranura oligorchis (Additional file 3: F).

In contrast, animal kingdom (91.073\%), mainly phyla Brachiopoda (lamp shells) and Mollusca (snails), served the major free-living, $18 \mathrm{~S}$ rDNA organisms detected in Tham Phang coastal water. Kingdoms of fungi (6.728\%), plants $(1.310 \%)$ and protists $(0.890 \%)$ were present in < $10 \%$ of the identified $18 \mathrm{~S}$ rDNA reads in Tham Phang (Figure 5). For fungi, Tham Phang coast contained proportionally more Ascomycota and Glomeromycota than Basidiomycota. Phyla belonging to other kingdoms whose percent compositions were greater than those in Tha 


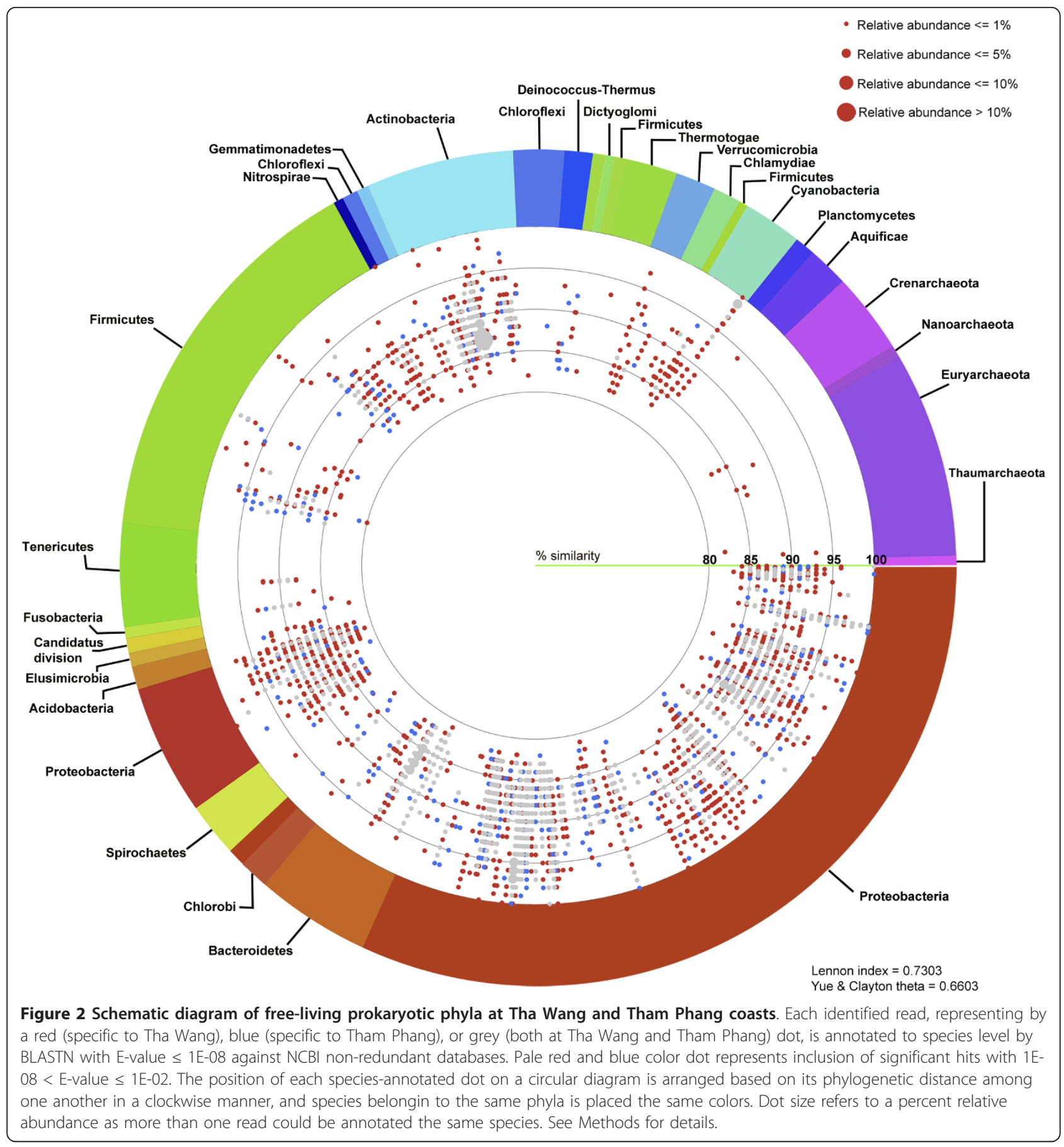

Wang included: (i) Chlorophyta, Xanthophyceae, and Stramenopiles from the kingdom of plants; and (ii) Porifera, Cnidaria, Arthropoda, Chordata, Echinodermata, Brachiopoda, Platyhelminthes, Mollusca, Gastrotricha and Priapulida from the kingdom of animals (Figure 5). Specifically, Platyhelminthes and Mollusca held over 10\% proportional abundant in Tham Phang than Tha Wang, with the Tham Phang-to-Tha Wang percent composition ratios of 16.391 and 13.610. Moreover, some phyla were only detected in Tham Phang, and they were: Phaeophyceae, Ochrophyta, Pinguiophyceae, Eustigmatophyceae, Labyrinthista, Sarcomastigophora, Neocallimastigomycota, Zygomycota, Euglenida, Hemichordata, Chaetognatha, Rhombozoa, Sipuncula, Acanthocephala and Nematomorpha (Figures 4 and 5). Examples of free-living, eukaryotic species found restricted to Tham Phang coast were Prosopanche americana, Rafflesia keithii, Acaulospora brasiliensis, Lingula anatine, Glycymeris pedunculata, 


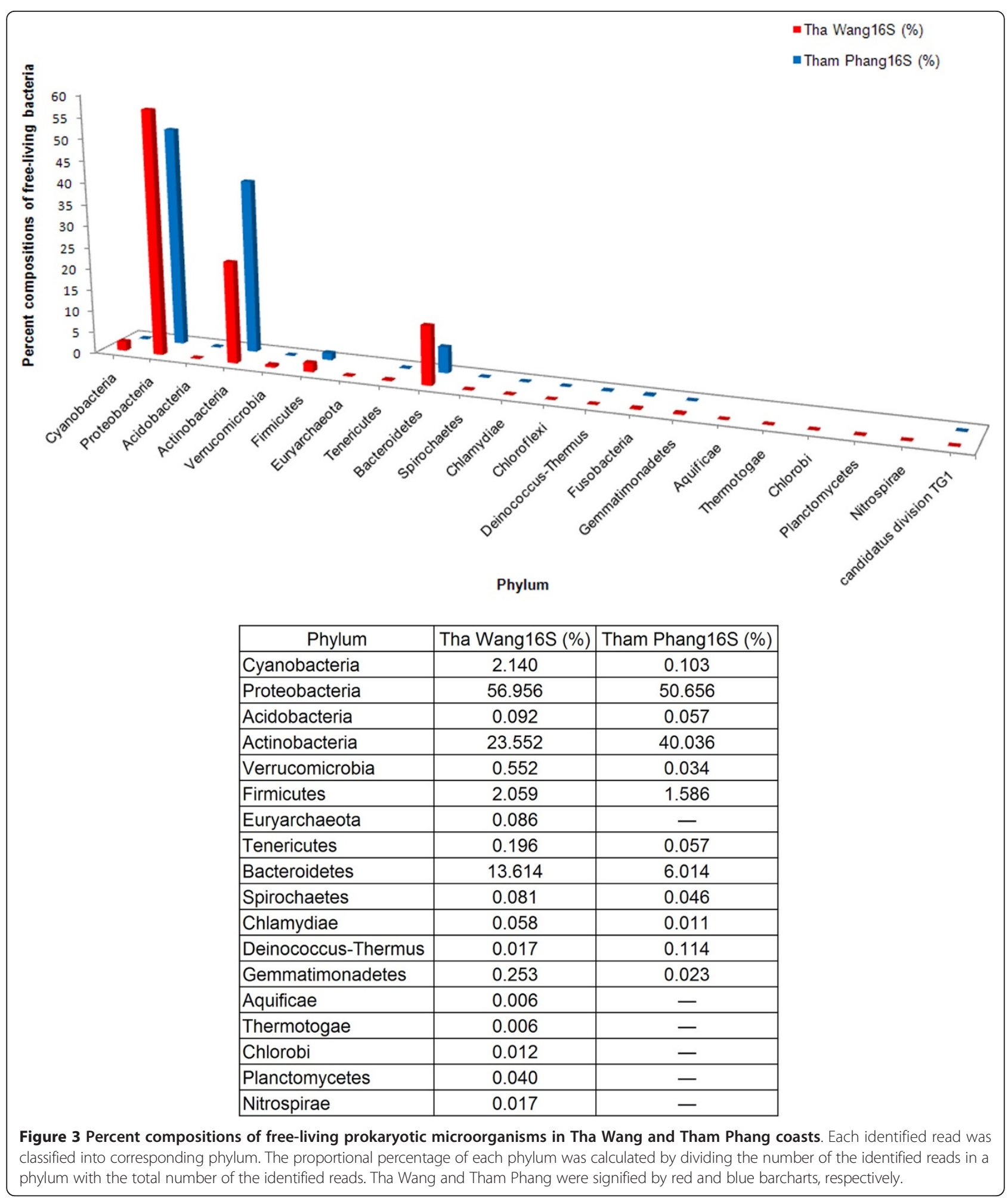

Pseudoscourfieldia marina, Hyalosira delicatula, Caloneis amphisbaena, Pinnularia acrosphaeria, Luticola goeppertiana, Leptocylindrus minimum, Chromonas cf., Lipomyces lipofer, Barnettozyma vustinii, Pichia salicaria, Wickernamiella domercqiae, Dipodascus magnusii, Pichia pastoris,
Abies homolepis, Zschokkella hildae, Paraphanostoma crassum, Actinoposthia beklemischevi, Sphaerospora truttae, Myxobilatus gasterostei, Neoactinomyxum eiseniellae, Sterreria psammicola, Selaginopsis cornigera, Oikopleura labradoriensis, Tesserocerus dewalquei, Clavispora 


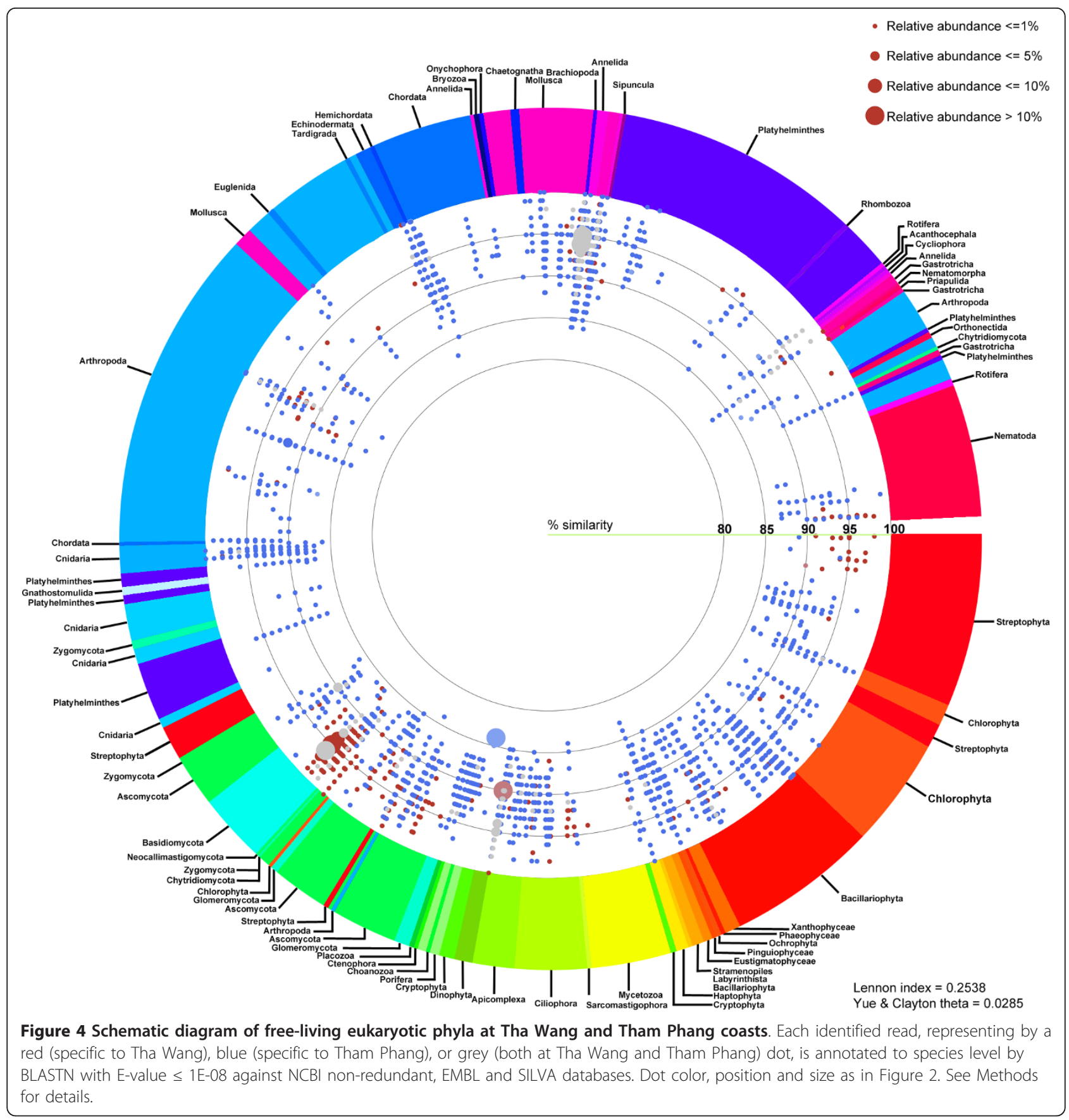

lusitaniae, Hyotissa numisma, Priapulus caudatus, Acantholeberis curvirostris, Eurycercus lamellatus, Ceriodaphnia megops, Malorerus randoi, Paramesopodopsis rufa, Ventsia tricarinata, Loxothylaeus texanus, Distaplia dubia, Branchiostoma floridae, Capitella sp., Melibe leonine, Sagitta crassa, Acanthocardia tuberculata, Ancylocoelium typicum, Scutellospora heterogama, Pteria macroptera, Peridinium balticum, Eubothrium crassum, Archotoplana holotricha, Phagocata sibirica, Paromalostomum fusculum, Chaetonotus neptuni, Bunonema franzi,
Laxus cosmopolitus and Paracyatholaimus intermedius (Additional file 3: F).

Analyses of free-living prokaryotic compositions representing coastal Tha Wang and Tham Phang compared with 67 GOS profiles

Population of free-living archaea and bacteria in Tha Wang and Tham Phang coasts were compared with the 16S rDNA metagenomic profiles from 67 GOS sites. Similarity between pairs of community structures were 
determined by Yue \& Clayton theta similarity coefficients (Thetayc) and Smith theta similarity coefficient (Thetan), using mothur $[17,18]$. The prokaryotic community structures between coastal Tha Wang and Tham Phang were found most closely related to each other (Thetayc 0.38756, Thetan 0.56919), and were somewhat distant from those of the GOS communities as described by the Thetayc and Thetan values that are close to 1.000 (Additional File 4). Identical community structures have zero Thetayc and Thetan value.

Comparing among the 67 GOS communities, the prokaryotic community structures in Tha Wang and Tham 
Phang coasts were most related to: GS022 (2-metre depth and 250 miles from Panama City, Panama, at latitude $6.493^{\circ} \mathrm{N}$ and longitude $\left.82.904^{\circ} \mathrm{W}\right)$, GS021 (1.6-m depth from Gulf of Panama coast, Panama, at $8.129^{\circ} \mathrm{N} 79.691^{\circ}$ W), GS028 (2-m depth from coastal Floreana, Ecuador, at $\left.1.217^{\circ} \mathrm{S} 90.319^{\circ} \mathrm{W}\right)$, and GS015 (1.7-m depth from Off Key West coast, Florida, the United States, at $24.488^{\circ} \mathrm{N}$ $83.07^{\circ} \mathrm{W}$ ) (Additional File 4). The principle coordinate analysis (PCoA) and phylogenetic tree apparently showed the prokaryotic compositions of GS022 to be most similar to those of Tha Wang and Tham Phang (Figures 6 and 7). Visualizing the prokaryotic communities among Tha Wang, Tham Phang and GS022, several conserved species as denoted by grey dots and many distancerelated species were found (Figures 8 and 9). Conserved species were in phyla Proteobacteria, Actinobacteria, Bacteroidetes and Cyanobacteria (Figures 8 and 9). Comparing between Tha Wang and Tham Phang, the prokaryotic community of GS022 was closer to that in Tha Wang. The Lennon and Yue \& Clayton theta similarity indices between Tha Wang and GS022 were 0.603 and 0.018, and between Tham Phang and GS022 were 0.396 and 0.003 . Conserved species between GS022 and Tha Wang, and not Tham Phang were Beutenbergia cavernae in phylum Actinobacteria, Halorhodospira halophila and Shewanella frigidimarina in Proteobacteria, and Prochlorococcus marinus in Cyanobacteria (Figure 8). Conserved species between GS022 and Tha Phang, and not Tha Wang were Rhodospirillum centenum and Pseudoalteromonas haloplanktis in Proteobacteria (Figure 9).
Particularly, Cyanobacteria species Synechococcus sp. and Prochlorococcus marinus in GS022 shared the great percentage of relative abundance with Tha Wang than Tham Phang. Still, some species were found restricted to GS022 and were not found in Tha Wang and Tham Phang, including Candidatus methanoregula, Methanosaeta thermophila, Methanosarcina mazei, Methanosphaerula palustris and Thermoplasma volcanium in phylum Euryarchaeota, Geobacillus sp. and Lysinibacillus sphaericus in Firmicutes, Laribacter hongkongensis, Methylobacterium chloromethanicum and Rickettsia africae in Proteobacteria, Acholeplasma laidlawii in Tenericutes, and Mycobacterium avium in Actinobacteria.

\section{Discussion}

Tha Wang and Tham Phang coasts were hypothesized to embrace dissimilar microbial species distribution and ecosystems, given that Tha Wang represented the more inhospitable coastal niche than Tham Phang, and despite both coasts locate in similar oceanographic positions. The hypothesis was consistent with previous reports by SMaRT that found overgrowth of phytoplanktons, zooplanktons and crabs in coastal Tha Wang (S. Rungsupa, personal communication). Along with its close bay geography, the massive increase of wastes through extensive numbers of islanders and industrialization were highly responsible for the poor quality of Tha Wang bay and coast.

This study represented the first study that identified microbial biodiversity of coastal Sichang island using metagenomics, and, in consistent with the hypothesis, the

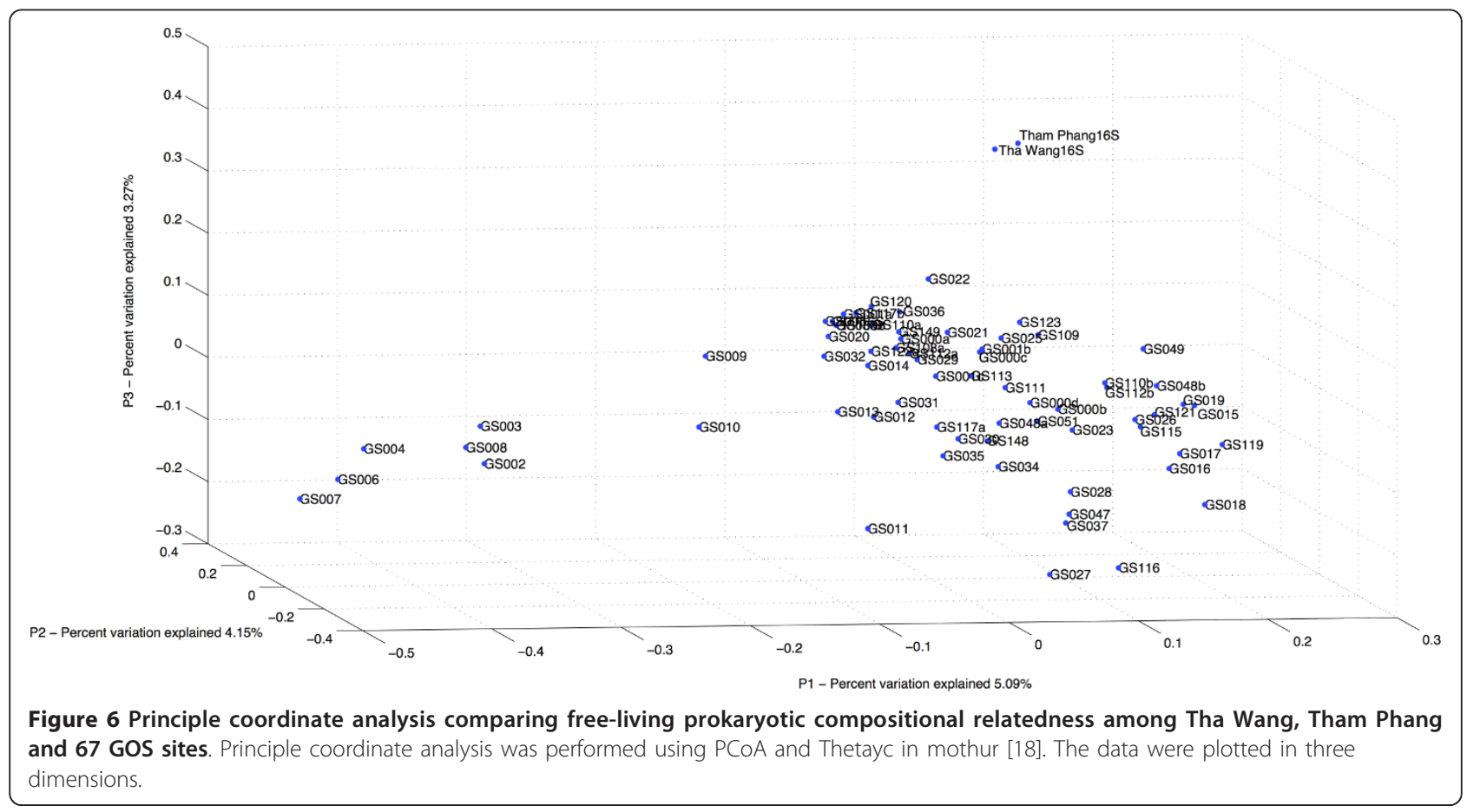




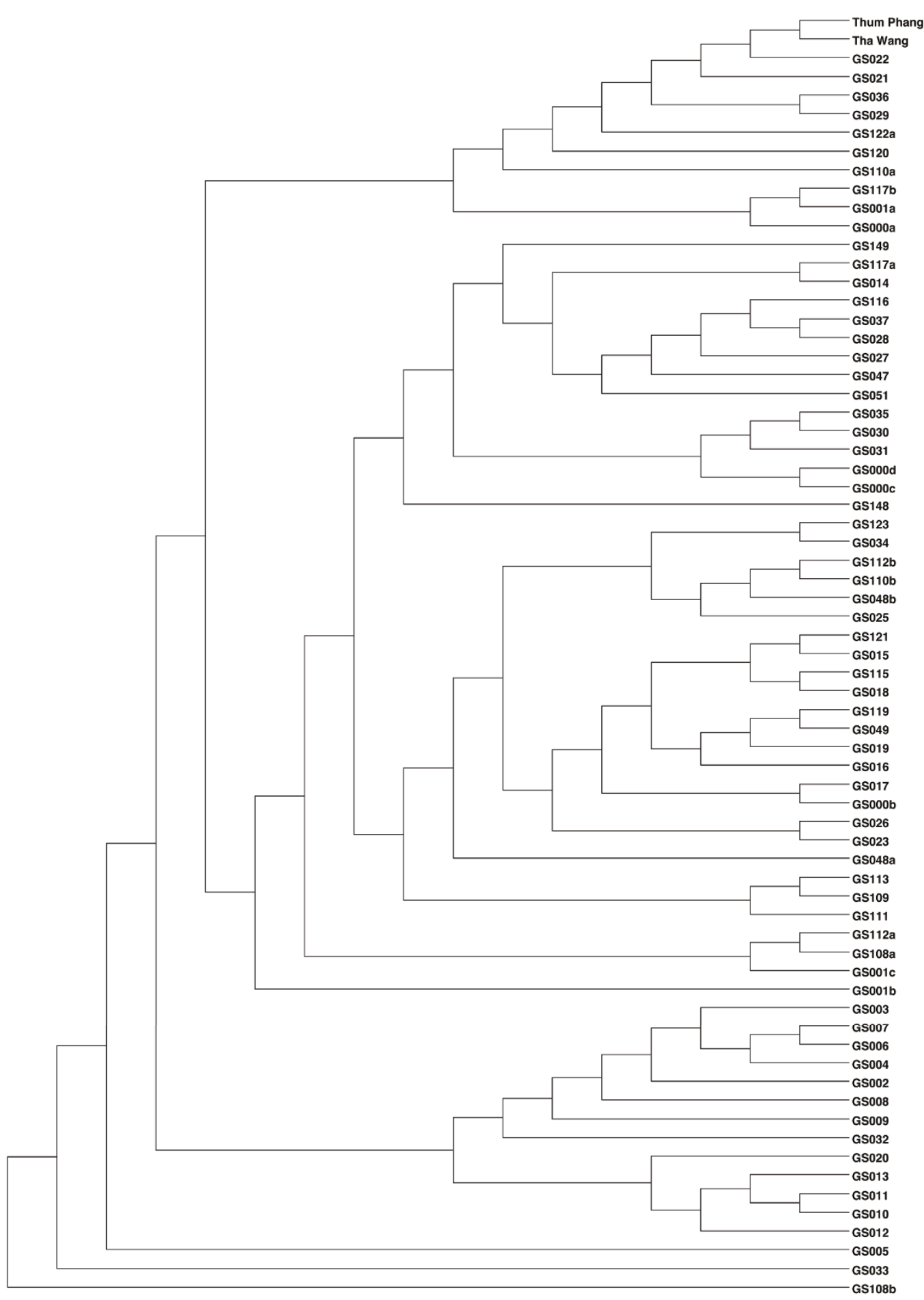

Figure 7 UPGMA tree showing distances of prokaryotic communities in Tha Wang, Tham Phang and 67 GOS sites. Distances between pairs of Tha Wang, Tham Phang and 67 GOS communities were based on the Thetayc reported in Table 2. All 16S rDNA sequences were aligned in NAST [73], following Kimura's two-parameter model [70]. The UPGMA distance tree was constructed at distance of 0.03 using mothur [18]. 


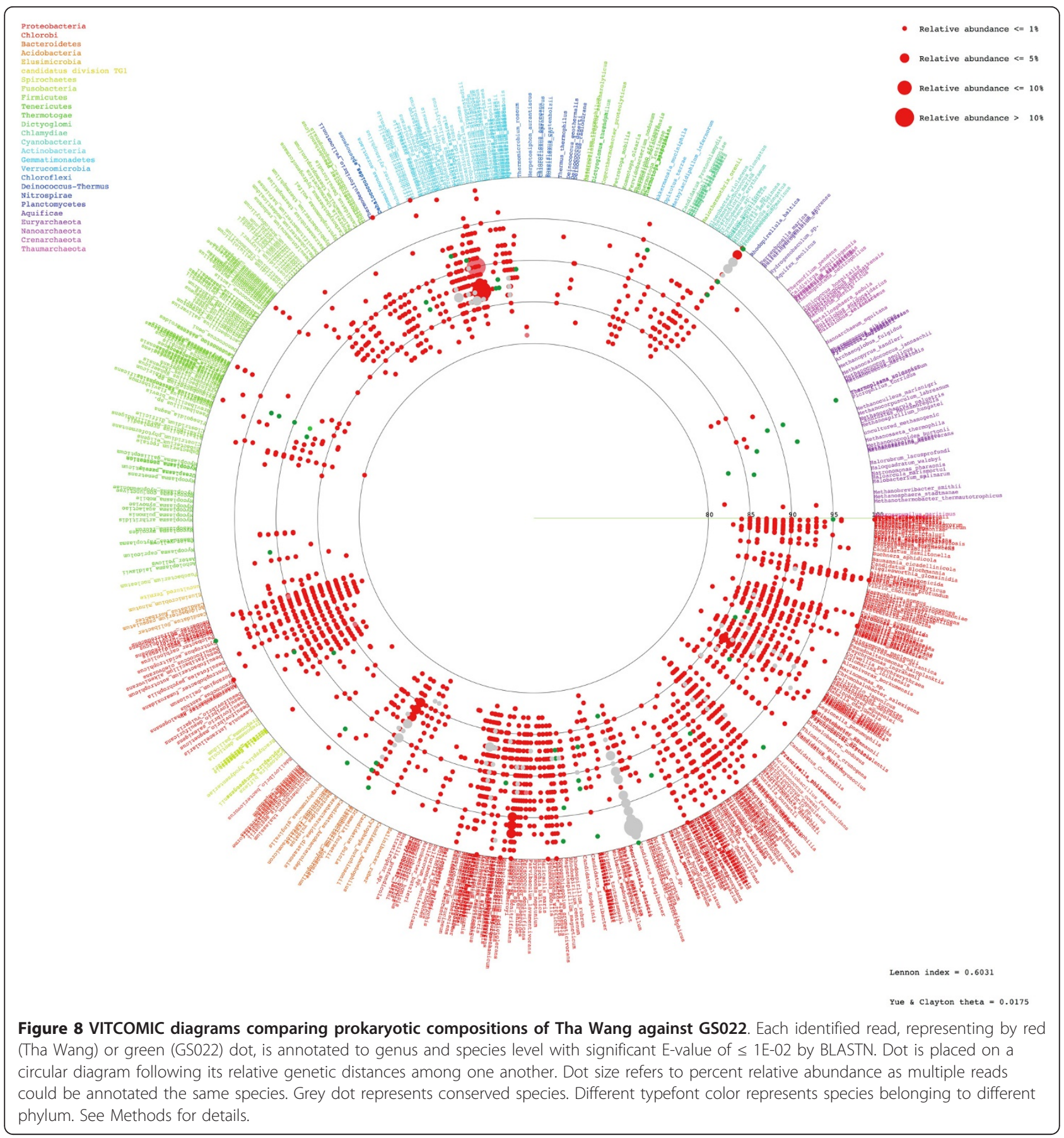

study discovered different physical and chemical water properties (Additional File 1) and microbial metagenomic profiles (Figures 2 and 4) between Tha Wang and Tham Phang coasts. The clearer water, the lower conductivity and the slightly higher salinity and $\mathrm{pH}$ in coastal Tham Phang were appropriate for aquatic lives, and supported the diversity in marine environments and microbial communities in Tha Wang and Tham Phang coasts. The finding of the greater salinity in Tham Phang coast was coherent with the monthly salinity reports by SMaRT [19] (S. Rungsupa, personal communication). Additionally, Tham Phang coast had the greater percent dissolved oxygen and the lower contents for all kinds of wastes, including organic mass, glass bottles, plastics, metals, hazardous materials, ammonium, nitrite, and phosphate than Tha Wang coast [5] (S. Rungsupa, personal communication and unpublished data). These signified the importance for analysing the microbial diversity in Tha Wang and Tham 


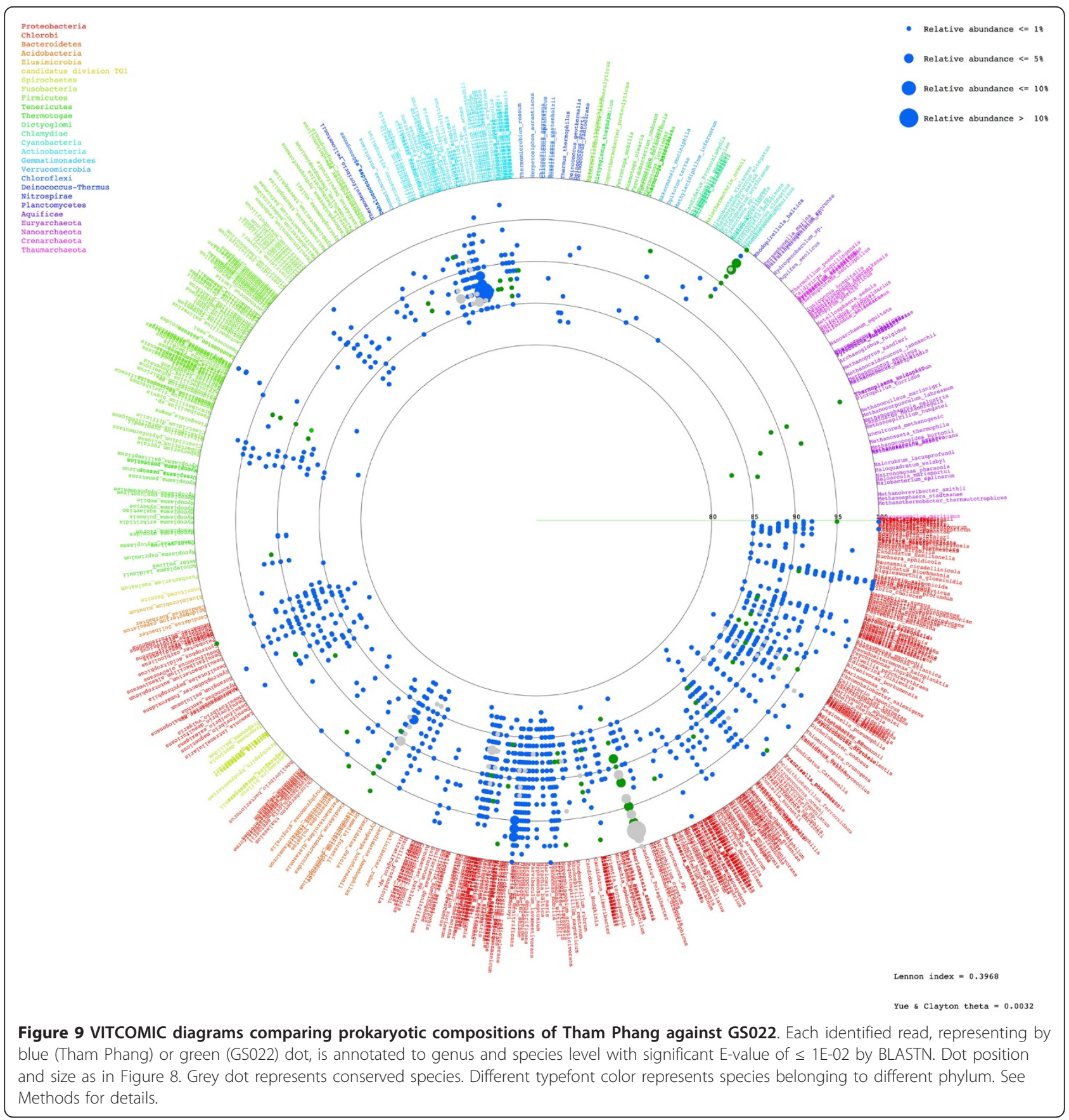

Phang coasts, and, particularly, for investigating the effects of the relatively close bay geography and intensive manmade activities on the microbial species and species distributions in coastal Tha Wang. As Tha Wang symbolizes one central pier for Thailand's cargo route with populated residents and varied sorts of industries, yet Tham Phang remains a quiet natural beach for tourists, this further emphasized the importance of better understanding the coastal microbial ecosystems around Sichang island.
Free-living microorganisms of $0.45-30$ micron in diameter size in approximate were trapped onto the filter papers, and their metagenomes were extracted. The total nucleic acid concentration of microorganisms of the two areas was averagely $0.45 \mathrm{ng} / \mathrm{ml}$ of seawater. The slightly greater metagenomic DNA concentration of free-living microorganisms in Tha Wang than Tham Phang indicated the total more amount of free-living microbiomes in Tha Wang coast (Additional file 2). 
For free-living $16 \mathrm{~S}$ rDNA species analyses, nearly $100 \%$ of the reliable read lengths (Tha Wang 99.902\%, Tham Phang 99.647\%) could be successfully annotated. While Proteobacteria, a major-reported bacterial phylum in global seafloor and seawater $[2,4]$, was unsurprisingly dominated in Tha Wang and Tham Phang coasts, more diversified and abundant archaea and bacteria, including pathogenic and harsh environment-dwelling species, were revealed in Tha Wang coast (Figure 2 and Additional files 3: A-C). Many species were even found uniquely or significantly predominated in Tha Wang coast, most of which could be related to its differentially ongoing activities that polluted the marine environment and stimulated outgrowing of prokaryotic communities. For instances, Bacteroidetes are abundant bacteria in animal and human feces, and were likely carried to Tha Wang coastal water via municipal wastewater. Bacteroidetes are opportunistic pathogens to humans [20]. Cyanobacteria, also known as blue-green bacteria or algae, though are oxygen-producers and account for $20-30 \%$ of the Earth's protosynthetic productivity [21], could produce harmful cyanotoxins under constraint circumstances generally as a result of human-polluted activities [22]. Microcystis aeruginosa is one example. Cyanotoxins, such as neurotoxins and endotoxins, are toxic to various aquatic lives and humans consuming these contaminated water or seafood $[23,24]$. Firmicutes constitute a large portion of mouse and human gut microbiome, and some, such as Clostridium and Bacillus, could cause human intestinal disease $[25,26]$. Firmicutes could produce endospores under a hostile environment [27] like Tha Wang. Verrucomicrobia and Gammatimonadetes are new phyla that are under-represented by culture, but are believed to be common in nature, especially in soils [28]. Ternicutes refer to bacteria with no cell wall, such as Mycoplasma and Ureaplasma, that could cause human respiratory and urogenital tract diseases [27]. Acidobacter are another new phylum believed to be widespread in nature, although a few had only been isolated due to the limitation of traditional cultivation methods. The first species of Acidobacter was isolated in 1991 [29-32]. Chlamydiae are obligate intracellular bacterial pathogens that often reside asymptomatically in a variety of hosts. Chlamydiae cause severe diseases in restricted hosts, particularly humans [33]. Indeed, Chlamydia trachomatis is responsible for the main bacterial cause of human's preventable blindness and sexually transmitted disease worldwide $[34,35]$. Euryarchaeota are methane-producing archaea that survive in high-salt and high-temperature conditions.

Thus, many $16 \mathrm{~S}$ rDNA species around Sichang island comprised archaea, which are often thermophiles, and thermophilic bacteria that could survive up to $122^{\circ} \mathrm{C}$. The thermophilic bacteria were among the earliest bacteria, and include Firmicutes, Thermotogae, Aquificae,
Actinobacteria, Deinococcus-Thermus and Chloroflexi [36]. Numerous archaea and thermophilic bacteria in coastal Tha Wang might be associated with tremendouse sewage drainage in Tha Wang area. Examples of species that could inhabit harsh environments and were distinctly found in Tha Wang included: sulfate-reducing Thermodesulfovibrio yellowstonii, originally isolated anaerobically from hot vent water in Yellowstone Lake, Wyoming, USA [37]; sulfur-reducing Petrotoga mobilis, obligate anaerobe that tolerates salty and high temperature and was first isolated from a North Sea oil-production well [38]; Halothermothrix orenii, a halophilic, thermophilic, fermentative, obligate anaerobe that could synthesize thermohalophilic enzyme and hydrogen for biotechnology [39]; Aquifex aeolicus, commonly found near hot springs and underwater volcanoes [40]; archaea Methanopyrus kandleri, originally discovered from the Gulf of California, USA, at a depth of 2000 metres [36]; and Thermotoga neapolitana and Thermotoga petrophila $[39,41]$. Firmicutes Halothermothrix orenii and all members of Thermotogae could also produce hydrogen from organic wastes, and some species such as Thermotoga neapolitana and Halothermothrix orenii could accumulate a considerate hydrogen quantity than the others $[36,41]$. In addition, Euryarchaeota Methanopyrus kandleri, Methanococcus aeolicus, Methanoculleus marisnigri, Methanocorpusculum labreanum and Methanothermobacter thermautotrophicus are natural carbon recycler and could produce methane from hydrogen and carbon dioxide. These archaea and bacteria are commonly detected in wastewater, sewage sludge and landfills $[42,43]$. Since the market demand for methane and hydrogen gases has increased yearly, using methanogenic- and hydrogenic-producing archaea and bacteria as biofuel producers represent one effective economical and environmental-sustainable venue [41].

Whereas serving as a credible resource for biofuel, Tha Wang coast also comprised many prokaryotes that could potentially cause diseases not only to humans but also to plants and other prokaryotic species in the ecosystems. For instances, Herpetosiphon aurantiacus in phylum Chloroflexi, which was firstly isolated from slime coat of algae from Birch Lake, Minnesota, USA [44], could secrete hydrolytic enzymes that are harmful to gram-positive and gram-negative bacteria [45]. Aster yellows was reported a leading cause of plant pathogen in both agricultural and nursery industries [46].

For Tham Phang, prokaryotic species advanced for biological decomposition and pharmaceutical production seemed to be more found. The relative proportion of Actinobacteria was almost 2 -fold predominated in Tham Phang (41.036\%) than Tha Wang (23.552\%) (Figure 3). Actinobacteria are common phylum of bacteria in soil and marine environments, and have a vital role in decomposition of organic materials, such as cellulose 
and chitin, and of other essential nutrients [47]. Actinobacteria, such as Streptomyces, are also well-known for secondary metabolite producers and significant sources for pharmaceutical usage, albeit some, such as Mycobacterium and Corynebacterium, are human pathogens [48]. Interestingly, Deinococcus-Thermus, which relative proportion was also greater in Tham Phang than Tha Wang, are extremely resistant to heat, cold, anaerobic condition, and radiation materials, and they could digest nuclear and many other toxic wastes $[36,49]$. This phylum might further help recuperate Tham Phang coast.

The similarities and differences in 16S rDNA species diversity and species richness between Tha Wang and Tham Phang were summarized by Lennon's and Yue \& Clayton theta indices of similarity (Figure 2). The lower than $74 \%$ of the similarity indices inferred a greater than $25 \%$ of difference in their prokaryotic species compositions, and supported the preliminary knowledge on Sichang geography and the results on water characteristics and $16 \mathrm{~S}$ rDNA pyrosequencing. Moreover, comparing the $16 \mathrm{~S}$ rDNA metagenomic profiles highlighted the greater proportions for high-temperature and energy-producing prokaryotes in Tha Wang, and for nutrient-recycling and drug-synthesizing prokaryotes in Tham Phang.

For free-living $18 \mathrm{~S}$ rDNA species analyses, while most of the $18 \mathrm{~S}$ rDNA reads $(99.949 \%)$ could be identified with significant BLASTN E-values, approximately half of Tha Wang reads $(48.532 \%)$ were identified. This suggested a large portion of distantly-related or undiscovered species in Tha Wang coast, and the research team is developing innovative bioinformatic approach to analyze these unidentified reads.

Among the identified 18S rDNA reads, Tha Wang and Tham Phang coasts shared few similarities in free-living eukaryotic compositions (Figure 4 and Additional file 3: D-F) as represented by the low Lennon and Yue \& Clayton theta similarity indices. In Tha Wang, almost $75 \%$ of the identified species were fungi (Basidiomycota $71.157 \%$, Ascomycota $3.060 \%$, Glomeromycota $0.317 \%$, Chytridiomycota $0.211 \%$ ), and the rests comprised kingdoms of animals, protists and plants (mostly unicellular algae), in orderly (Figure 5). On the opposite, only $6.728 \%$ of the $18 \mathrm{~S}$ rDNA reads in Tham Phang were fungi and with the different fungal compositions than those of Tha Wang. Basidiomycota and Chytridiomycota were minutely present in Tham Phang, while Ascomycota were more present. Species in animal kingdom (91.073\%) were the major $18 \mathrm{~S}$ rDNA population, and the least dominated species remained in the kingdoms of plants $(1.310 \%)$ and protists $(0.089 \%)$, most of which were unicellular and have chloroplasts (Figures 4 and 5). Overall, abundant population of fungi were present in Tha Wang, whereas small eukaryotes in animal kingdom were more common in Tham Phang. These differences likely reflected the differences in ecosystems between Tha Wang and Tham Phang coasts. The immense proportion of animals supported the physical and chemical characteristics of Tham Phang bay and water that was more appropriate for aquatic lives, stressing the fruitfulness of aquatic lives in Tham Phang compared with Tha Wang. Brachiopoda and Mollusca were the common species reported in Sichang island (S. Piyatiratitivora$\mathrm{kul}$ and S. Rungsupa, personal communications), and the frequent finding of the DNAs corresponding to these two phyla in Tham Phang was possible, as the eggs and larvae of these early developmental phase could have sizes smaller than $30 \mu \mathrm{m}$ and thus could pass through the first filtration step. Larvae of Brachiopoda were distasteful for fish and crustaceans, and could stay in water for months; yet, they are vulnerable to pollution and were used as a measure of environmental conditions in an oil terminal in Russia and in Japan [50]. Mollusca are accounted for the largest marine phylum, and served as food and pearls for humans, so the number has been declining globally [51]. Moreover, some animals could be microscopic in sizes, such as species in Gastrotricha and Arthropoda. Meanwhile, marine fungi generally inhabited driftwood and are rare as free-living, so the high proportion of fungi in Tha Wang might be associated with the released wastes from residents and industries [52,53]. Other protists, previously considered lower fungi, were also denoted in Tha Wang, such as Mycetozoa.

The metagenomic analyses for $18 \mathrm{~S}$ rDNA profiles in Tha Wang and Tham Phang were consistent with the analyses for the $16 \mathrm{~S}$ rDNA profiles in that a large proportion of harsh-dwellers, including biofuel producers, were in Tha Wang, while a large proportion of decomposers and drug-producers were in Tham Phang. For examples, Ascomycota are important decomposers and medical producers [54-56], and the proportion of this phylum was found two-times in Tham Phang (Figure 5). Genera in Asocimycota are such as Pennicilium, Tolypocladium and Saccharomyces.

Moreover, the 16S rDNA metagenomic profiles inhabiting Tha Wang and Tham Phang coasts were compared to those of 67 GOS sites. High Thetayc and Thetan coefficients (Additional File 9) and no overlay of principle coordinate analysis (Figure 6) indicated unique prokaryotic ecosystems in coastal Tha Wang and Tham Phang, and emphasized the significant contribution of our $16 \mathrm{~S}$ rDNA and 18S rDNA metagenomic profiles in fulfilling the knowledge on global marine ecosystems. The prokaryotic community structures of GS022, GS021, GS015 and GS028 were more closely to those of Tha Wang and Tham Phang coasts based on Thetayc and Thetan coefficients (Additional File 9). Principle coordinate analysis (Figure 6) and phylogenetic clustering (Figure 7) confirmed the GS022 prokaryotic community to be closest to the Tha Wang and Tham Phang prokaryotic 
communities (Figure 7). Some variations in phylogenetic clustering and PcoA were results of the differences in algorithms used for the PcoA and neighbour-joining tree construction. GS022 represents the prokaryotic communities inhabiting surface water in the Pacific Ocean 250 miles from Panama City, Panama, where the climate was tropical and the ecosystem was largely diverse like Thailand. Panama has tropical rain forest and temperature of 18.4-34. $2^{\circ} \mathrm{C}$ in February (average $26.3^{\circ} \mathrm{C}$ ). Besides, the economy of the Panama City partly depends on trading and shipping industries like Tha Wang coast, causing its marine environment to be somehow more similar to that of Tha Wang than Tham Phang (Figures 8 and 9). The Lennon and Yue \& Clayton theta similarity indices between Tha Wang and GS022 were greater than those between Tham Phang and GS022. Yet, some species distinct to GS022, including human pathogens and waterquality indicators, could be associated with particular activities dominated around the Panama City. Meanwhile, uniquely found species in Tha Wang were such as Thermodesulfovibrio yellowstonii in phylum Nitrospirae. Although residual amount of sulphate is typical in seawater, sediment, and water rich in decaying organic material, agricultures and shipping industries could produce an excess of sulfate, leading to the presence of this microorganism in addition to other sulfate-reducing species possible. Thermodesulfovibrio yellowstonii could help other sulfate-reducing species in coastal Tha Wang to reduce sulfate to hydrogen sulfide and to degrade organic materials by oxidizing organic compounds or molecular hydrogen to obtain energy [36,37]. Examples of other species unique in coastal Tha Wang were Kosmotoga olearia in Thermotogae and Rhodopirellula baltica in Planctomycetes. Kosmotoga olearia was also present in Troll B oil platform in the North Sea, and Rhodopirellula baltica was also present in marine brackish Baltic sea (https://portal.camera.calit2.net/gridsphere/gridsphere). These species could also degrade complex carbohydrates in industrial wastewater, and members in Thermotogae could inhabit extreme environments, such as municipal wastewater treatment, oil production water and lowtemperature bioreactors, supporting the feasibility of detecting these species in Tha Wang $[36,57,58]$.

However, to better understand the Sichang marine ecosystems, similar analyses might be conducted at different time of the year, for example, in a different season, and at different time of the day. Once the data on 18S rDNA profiles by the GOS become available, the understanding of similarities and differences among the eukaryotic communities in coastal Tha Wang and Tham Phang against the GOS is also essential. In particular, comparative analyses of free-living fungal biodiversity help elucidate marine microbial communities, and yet many free-living fungi are obligate parasites to humans and marine organisms. Currently, we are working on identifying the biodiversity of archaea, bacteria and small eukaryotes at other significant marine and soil sites of Thailand. Such information will provide a complete database for microbiome profiles and enhance the understanding of local and global, marine and soil ecosystems.

Finally, finding of tremendously diverse species, including identified and unidentified species, showed the advantages of metagenomics in obtaining conclusive archaea, bacteria and small eukaryotic databases, helping to define the marine ecosystems. This study identified free-living prokaryotic and eukaryotic species diversity and differences in their compositions in Tha Wang and Tham Phang coasts. The study helped better understanding and better management of the marine microbial ecosystems around Sichang island, and the comparative data analyses share valuable knowledge for GOS databases. The results also suggested Tha Wang coast as potential one resource for discovery and isolation of biotechnology and industrial enzymes, and Tham Phang coast for discovery and isolation of pharmaceutical compounds. Nevertheless, all identified species in the present study merely represented the significant BLASTN hits to the identified $16 \mathrm{~S}$ and $18 \mathrm{~S}$ rDNA species. Hence, each annotation could mean the exact species match or the phylogenetically related species, depending on the E-values and the percent alignment coverage between the hit and the target sequences.

\section{Conclusions}

Metagenomics allowed the culture-independent identification of $16 \mathrm{~S}$ and $18 \mathrm{~S}$ rDNA profiles of microorganisms residing in Tha Wang and Tham Phang coasts of Sichang island. Many similarities and differences in biodiversity and species distributions in both coasts were detected, and might be associated with the different bay geography and water conditions posed by Tha Wang and Tham Phang coasts. These metagenomic profiles helped better understanding of marine microbial ecosystems around Sichang island, and contributed supportive databases towards the world ocean metagenomic databases. Analysing the data together with the 67 GOS databases allowed the better interpretation of the global marine ecosystems.

\section{Methods}

\section{Coastal water sample collection}

Seafloor and seawater of Tha Wang and Tham Phang coasts (Figure 1) were collected into separated sterile glass containers on 19 February 2011, around 12:0013:00 hrs. For each site, water color was noted, and onsite measurements for temperature, $\mathrm{pH}$, salinity and conductivity were performed. The two coastal areas are not vast, and three independently replicate seafloor and seawater samples per site, as well as the positions for each water sample collection were as guided by the 
SMaRT scientists for the most representative sample collections of each coastal area. Note the samples belonging to the same sample site were pooled for pyrosequencing. All samples were transported on ice, stored in $4^{\circ} \mathrm{C}$ and were processed for the next steps within 14 days.

\section{Metagenomic DNA extraction and DNA quality examination}

Each water sample was poured through four-layered sterile cheesecloth to remove debris and large-size organisms. Then, free-living prokaryotes and eukaryotes whose sizes were larger than $0.45 \mu \mathrm{m}$ were collected using a sterile 0.45 -micron filter (Merck Millipore, Massachusetts, USA). Total nucleic acids were isolated using Metagenomic DNA Isolation Kit for Water (Epicentre, Wisconsin, USA), following the manufacturer's instructions. The isolated metagenomic DNA should be randomly sheared and appear around $40 \mathrm{~kb}$ in size [59]. The extracted metagenomes were analyzed for DNA quality and concentration by agarose gel electrophoresis and $A_{260} / A_{280}$ nanodrop spectrophotometry.

\section{PCR generation of pyrotagged $16 \mathrm{~S}$ and $18 \mathrm{~S}$ rDNA sequences}

For broad-range PCR amplification of prokaryotic $16 \mathrm{~S}$ rDNAs, universal prokaryotic 338F (forward) and 803R (reverse) primers were used to amplify a 466-nucleotide sequence covering V3 and V4 regions of the 16S rRNA gene (Escherichia coli strain MYL-4, GenBank Accession no. HQ738475) [60-62]. The forward and reverse pyrotagged-16S rDNA primers for Tha Wang were 5'-TC TCTGTGACTCCTACGGGAGGCAGCAG-3' and 5'-TC TCTGTGCTACCAGGGTATCTAATC-3', where italic sequences represent the tag sequences. The forward and reverse pyrotagged-16S rDNA primers for Tham Phang were 5'-TCTACTCGACTCCTACGGGAGGCAGCAG-3' and 5'-TCTACTCGCTACCAGGGTATCTAATC-3' [63]. For broad-range PCR amplification of eukaryotic $18 \mathrm{~S}$ rDNAs, universal eukaryotic 1A (forward) and 516R (reverse) primers were used to amplify a 560-nucleotide sequence at the 5 '-end of the $18 \mathrm{~S}$ rRNA gene (Candida sp. Y15 EG-2010, GenBank Accession no. HM161753) [64-66]. The forward and reverse pyrotagged-18S rDNA primers for Tha Wang were 5'-AGAGTATGCTGGTTGATCCTGCCAGT-3' and 5'-AGAGTATGACCAGACTTGCCCTCC3 , where italic sequences represent the tag sequences. The forward and reverse pyrotagged-18S rDNA primers for Tham Phang were 5'-ATGACTCGCTGGTTGATCCTGCCAGT-3' and 5'-ATGACTCGACCAGACTTGCCCTCC-3' [63]. For each sample, a $50-\mu$ PCR reaction comprised $1 \times$ EmeraldAmp ${ }^{\circledR}$ GT PCR Master Mix (TaKaRa, Shiga, Japan), $0.3 \mu \mathrm{M}$ of each primer, and $100 \mathrm{ng}$ of the metagenomic DNA. The PCR conditions were $95^{\circ} \mathrm{C}$ for $4 \mathrm{~min}$, and
30-35 cycles of $94^{\circ} \mathrm{C}$ for $45 \mathrm{~s}, 50^{\circ} \mathrm{C}$ for $55 \mathrm{~s}$ and $72^{\circ} \mathrm{C}$ for $1 \mathrm{~min} 30 \mathrm{~s}$, followed by $72^{\circ} \mathrm{C}$ for $10 \mathrm{~min}$.

\section{Gel purification and pyrosequencing of pre-tagged $16 \mathrm{~S}$ and $18 \mathrm{~S}$ rDNA fragments}

PCR products of about 466 (16S rDNA) and 560 (18S rDNA) nucleotides in length were excised from agarose gels, and were purified using PureLink ${ }^{\circledR}$ Quick Gel Extraction Kit (Invitrogen, New York, USA). 400 ng each of pyrotagged Tha Wang and Tham Phang $16 \mathrm{~S}$ rDNAs and $100 \mathrm{ng}$ each of pyrotagged Tha Wang and Tham Phang 18S rDNAs were pooled and used for pyrosequencing on an eight-lane Picotiter plate. Pyrosequencing was performed using the 454 GS FLX system (Roche, Branford, CT).

\section{Sequence annotation and microbial composition analyses}

Sequences were categorized based on their appended pyrotag-sequences, and sequences of less than 100 nucleotides were discarded. The sequences were annotated, visualized and computed for taxonomic compositions and evolutionary distances using VITCOMIC (Visualization tool for Taxonomic Compositions of Microbial Community) [10] with some modifications. In brief, a library for $16 \mathrm{~S}$ rDNA species were constructed from NCBI non-redundant [11], RDP $[8,12]$ and Greengenes [13] databases, and a library for 18S rDNA species were constructed from NCBI non-redundant [11], EMBL $[14,15]$ and SILVA $[16]$ databases. Each read was annotated using BLASTN [67] or RNAmmer [68] with default parameters, unless identified. Percent relative abundance for each phylum was computed from the frequency of reads in the phylum divided by the total number of identified reads. In VITCOMIC, multiple sequences were aligned following MAFFT 6.713 with default parameters [69], genetic distances were calculated following Kimura's two-parameter model [70], and a neighbor-joining tree was constructed using PHYLIP 3.69 [10,71]. Similarity indices of taxonomic compositions among different sample groups were determined based on Lennon and Yue \& Clayton theta similarity indices [10,72]. Additionally, the $16 \mathrm{~S}$ rDNA data were compared with those of the GOS (https://portal.camera.calit2.net/gridsphere/gridsphere) $[1,3,8,9]$, using Yue \& Clayton theta similarity coefficients (Thetayc) and Smith theta similarity coefficient (Thetan) in mothur $[17,18]$. The closer the similarity coefficient to 0.000 indicated the more similarity in community structures. PCoA was plotted in three-dimensions using mothur [18]. The Tha Wang and Tham Phang 16S rDNA data and the 67 GOS data and their Thetayc were used for an unweighted pair group method with arithmetic mean (UPGMA) clustering by mothur [18], given that their multiple sequence alignment were performed using NAST [73]. The results were manually inspected to 
ensure properly sequence annotation, clustering, and phylogenetic tree relationship.

\section{Additional material}

Additional File 1: Marine characteristics of Tha Wang coast, Tham Phang coast, and 67 GOS sites. Geographical and chemical properties include site description, latitude and longitude, depth level, temperature, salinity in practical salinity unit (psu; formerly called parts per thousand), $\mathrm{pH}$ and conductivity. Information of all GOS, in numerical order based on the GOS station names, was downloaded from https://portal.camera. calit2.net/gridsphere/gridsphere.

Additional File 2: Agarose-electrophoretic gel showing 3 Tha Wang and 3 Tham Phang metagenomic DNAs. Left lane is a $10 \mathrm{~kb}$ DNA marker where the top band is at $12 \mathrm{~kb}$, and right lane is $80 \mathrm{ng}$ of a $40 \mathrm{~kb}$ fosmid control.

Additional File 3: Schematic diagrams of free-living prokaryotic (A-C) and eukaryotic (D-F) species at Tha Wang and Tham Phang coasts. For 165 rDNA reads, each identified read, representing by a red (Tha Wang) or blue (Tham Phang) dot, is annotated to genus and species level by BLASTN with E-value $\leq 1 \mathrm{E}-08$ against NCBI nonredundant databases. For 185 rDNA reads, each identified read, representing by a red (Tha Wang) or blue (Tham Phang) dot, is annotated to genus and species level by BLASTN with E-value $\leq 1 \mathrm{E}-08$ against NCBI non-redundant, EMBL and SILVA databases. Pale red and blue color dot represents inclusion of significant hits with 1E-08 $<$ Evalue $\leq 1 \mathrm{E}-02$. In $\mathbf{C}$ and $\mathbf{F}$, grey dot represents species found in both Tha Wang and Tham Phang. Each dot was placed on a circular diagram in respect to its species annotation. Species were arranged following their relative genetic distances among one another. Dot size refers to a percent relative abundance as more than one read could be annotated the same species. Different typefont color represents species belonging to different phylum. See Methods for details.

Additional File 4: Similarity coefficient values representing relatedness among pairs of prokaryotic community structures of Tha Wang, Tham Phang and 67 GOS. Different pairs of the 165 rDNA metagenomic profiles belonging to coastal Tha Wang, coastal Tham Phang, and 67 GOS were compared via Thetayc and Thetan similarity coefficients. Thetayc and Thetan were computed using mothur with default parameters and at distance of 0.03 [18]. The results were ranged in the order starting from the most closely related to the farthest related pairs of communities. Identical community structures have Thetayc and Thetan equal to zero.

\section{Acknowledgements}

The authors thank S. Piyatiratitivorakul and S. Rungsupa for critical manuscript discussion, and S. Thaniyavarn, D. Sangsrakru, K. Kidmoa and A. Klanchui for general support. The authors also appreciate Sichang Marine Science Research and Training Station. This work was supported by Research Funds from the Faculty of Science, Chulalongkorn University, under the Project for Interdisciplinary Research, which Targeted to Collaborate with the Leading World Class University (to N. Somboonna). S. Tongsima would like to acknowledge the three grants that partially supported this work, namely 1) the Office of the Higher Education Commission and Mahidol University under the National Research Universities Initiative 2) the Thailand Research Fund (TRF) under Project no. RSA5480026 and 3) the "Research Chair Grant" National Science and Technology Development Agency.

This article has been published as part of BMC Genomics Volume 13 Supplement 7, 2012: Eleventh International Conference on Bioinformatics (InCoB2012): Computational Biology. The full contents of the supplement are available online at http://www.biomedcentral.com/bmcgenomics/ supplements/13/S7.

\section{Author details}

'Department of Microbiology, Faculty of Science, Chulalongkorn University, Bangkok 10330, Thailand. ${ }^{2}$ Genome Institute, National Center for Genetic
Engineering and Biotechnology, Klong 1, Klong Luang, Pathum thani 12120, Thailand.

\section{Authors' contributions}

NS conceived of the study, collected samples, carried out molecular biology experiments, participated in and coordinated the data analysis, draft the manuscript. AA participated in study design and data analysis. AW performed data analysis. SCT carried out pyrosequencing. SDT participated in data analysis, and helped to draft the manuscript. All authors read and approved the final manuscript.

\section{Competing interests}

The authors declare that they have no competing interests.

Published: 13 December 2012

\section{References}

1. Vener JC, Remington K, Heidelberg JF, Halpern AL, Rusch D, Eisen JA, Wu D, Paulsen I, Nelson KE, Nelson W, Fouts DE, Levy S, Knap AH, Lomas MW, Nealson K, White O, Peterson J, Hoffman J, Parsons R, Baden-Tillson H, Pfannkoch C, Rogers Y-H, Smith HO: Environmental genome shotgun sequencing of the Sargasso Sea. Science 2004, 304:66-74.

2. Biers EJ, Sun S, Howard EC: Prokaryotic genomes and diversity in surface ocean waters: interrogating the global ocean sampling metagenome. Appl Environ Microbiol 2009, 75:2221-2229.

3. Yooseph S, Nealson KH, Rusch DB, McCrow JP, Dupont CL, Kim M, Johnson J, Montgomery R, Ferriera S, Beeson K, Williamson SJ, Tovchigrechko A, Allen AE, Zeigler LA, Sutton G, Eisenstadt E, Rogers Y-H, Friedman R, Frazier M, Venter JC: Genomic and functional adaptation in surface ocean planktonic prokaryotes. Nature 2010, 468:60-66.

4. Zinger L, Ammaral-Zettler LA, Fuhrman JA, Horner-Devine MC, Huse SM, Welch DBM, Martiny JBH, Sogin M, Bortius A, Ramette A: Global patterns of bacterial beta-diversity in seafloor and seawater ecosystems. PLOS ONE 2011, 6:e24570.

5. Chantanawisuti N, Piyatiratitivorakul S, Menasveta P: Types and annual distribution of garbages around the shore of Sichang Islands. Thai J Aquat Sci 1996, 2:108-116.

6. Lane DJ, Pace B, Olsen GL, Stahl DA, Sogin ML, Pace NR: Rapid determination of $16 \mathrm{~S}$ ribosomal RNA sequences for phylogenetic analyses. Proc Natl Acad Sci USA 1985, 82:6955-6959.

7. Kennedy J, Flemer B, Jackson SA, Lejon DPH, Morrissey JP, Ógara F, Dobson ADW: Marine metagenomics: new tools for the study and exploitation of marine microbial metabolism. Mar Drugs 2010, 8:608-628.

8. Rusch DB, Halpern AL, Sutton G, Heidelberg KB, Williamson S, Yooseph S, Wu D, Eisen JA, Hoffman JM, Remington K, Beeson K, Tran B, Smith H, Baden-Tillson H, Stewart C, Thorpe J, Freeman J, Andrews-Pfannkoch C, Venter JE, Li K, Kravitz S, Heidelberg JF, Utterback t, Rogers Y-H, Falcón LI, Souza V, Bonilla-Rosso G, Eguiarte LE, Karl DM, Sathyendranath S, et al: The Sorcerer II Global Ocean Sampling expedition: northwest Atlantic through eastern tropical Pacific. PLOS Biol 2007, 5:e77.

9. Shaw AK, Halpern AL, Beeson K, Tran B, Venter JC, Martiny JBH: It's all relative: ranking the diversity of aquatic bacterial communities. Environ Microbiol 2008, 10:2200-2210.

10. Mori H, Maruyama F, Kurokawa K: VITCOMIC: visualization tool for taxonomic compositions of microbial communities based on $16 \mathrm{~S}$ rRNA gene sequences. BMC Bioinformatics 2010, 11:332.

11. Sayers EW, Barrett T, Benson DA, Bolton E, Bryant SH, Canese K, Chetvernin V, Church DM, DiCuccio M, Federhen S, Feolo M, Geer LY, Helmberg W, Kapustin Y, Landsman D, Lipman DJ, Lu Z, Madden TL, Madej T, Maglott DR, Marchler-Bauer A, Miller V, Mizrachi I, Ostell J, Panchenko A, Pruitt KD, Schuler GD, Sequeira E, Sherry ST, Shumway M, et al: Database resources of the National Center for Biotechnology Information. Nucleic Acids Res 2010, 38:D5-D16.

12. Maidak BL, Cole JR, Liburn TG, Parker CT Jr, Saxman PR, Farris RJ, Garrity GM, Olsen GJ, Schmidt TM, Tiedje JM: The RDP-II (ribosomal database project). Nucleic Acids Res 2001, 29:173-174.

13. McDonald D, Price MN, Goodrich J, Nawrocki EP, DeSantis TZ, Probst A, Anderson GL, Knight R, Hugenholtz P: An improved Greengenes taxonomy with explicit ranks for ecological and evolutionary analyses of bacteria and archaea. ISME J 2012, 6:610-618, doi:10.1038/ismej.2011.139. 
14. Brunak S, Danchin A, Hattori M, Nakamura H, Shinozaki K, Matise T, Preuss D: Nucleotide sequence database policies. Science 2002, 298:1333.

15. Leinonen R, Akhtar R, Birney E, Bower L, Cerdeno-Tárraga A, Cheng Y, Cleland I, Faruque N, Goodgame N, Gibson R, Hoad G, Jang M, Pakseresht N, Plaister S, Radhakrishnan R, Reddy K, Sobhany S, Hoopen PT, Vaughan R, Zalunin V, Cochrane G: The European nucleotide archive. Nucleic Acids Res 2011, 39:D28-31

16. Pruesse E, Quast C, Knittel K, Fuchs BM, Ludwig W, Peplies J, Glöckner FO: SILVA: a comprehensive online resource for quality checked and aligned ribosomal RNA sequence data compatible with ARB. Nucleic Acids Res 2007, 35:7188-7196.

17. Yue JC, Clayton MK: A similarity measure based on species proportions. Commun Stat Theor Methods 2005, 34:2123-2131.

18. Schloss PD, Westcott SL, Ryabin T, Hall JR, Hartmann M, Hollister EB, Lesniewski RA, Oakley BB, Parks DH, Robinson CJ, Sahl JW, Stres B, Thallinger GG, Horn DJV, Weber CF: Introducing mothur: open-source, platform-independent, community-supported software for describing and comparing microbial communities. Appl Environ Microbiol 2009, 75:7537-7541.

19. Antonov Jl, Locarnii RA, Boyer TP, Mishonov AV, Garcia HE: In World ocean atlas 2005. Washington, DC: U.S. Government Printing Office;Levitus S 2006.

20. Savichtcheva O, Okayama N, Okabe S: Relationships between Bacteroides $16 \mathrm{~S}$ rRNA genetic markers and presence of bacterial enteric pathogens and conventional fecal indicators. Water Res 2007, 41:3615-3628.

21. Pisciotta JM, Zou Y, Baskakov V: Light-dependent electrogenic activity of Cyanobacteria. PLOS ONE 5:e10821.

22. Lam CWY, Ho KC: Red tides in Tolo Harbor, Hong Kong. In Red tides. Biology, environmental science and toxicology. New York: Elsevier;Okaichi T, Anderson DM, Nemoto T 1989:49-52.

23. Flewelling $L$, Naar JP, Abbott JP, Baden DG, Barros NB, Bossart GD, Bottein M-YD, Hammond DG, Haubold EM, Heil CA, Henry MS, Jacocks HM, Leighfield TA, Pierce RH, Pitchford TD, Rommel SA, Scott PS, Steidinger KA, Truby EW, Dolah FMV, Landsberg JH: Red tides and marine mammal mortalities. Nature 2005, 435:755-756.

24. Walsh CJ, Leggett SR, Carter BJ, Colle C: Effects of brevetoxin exposure on the immune system of loggerhead sea turtles. Aquat Toxicol 2010, 97:293-303.

25. Ley RE, Bäckhed F, Turnbaugh P, Lozupone CA, Knight RD, Gordon Jl: Obesity alters gut microbial ecology. Proc Natl Acad Sci USA 2005, 102:11070-11075.

26. Ley RE, Peterson DA, Gordon Jl: Ecological and evolutionary forces shaping microbial diversity in the human intestine. Cell 2006, 124:837-848.

27. Wolf M, Müller T, Dandekar T, Pollack JD: Phylogeny of Firmicutes with special reference to Mycoplasma (Mollicutes) as inferred from phosphoglycerate kinase amino acide sequence data. Int J Syst Evol Microbiol 2004, 54:871-875.

28. Cho S-T, Tsai S-H, Ravindran A, Selvam A, Yang S-S: Seasonal variation of microbial populations and biomass in Tatachia grassland soils of Taiwan. Environ Geochem Health 2008, 30:255-272.

29. Kishimoto N, Kosako Y, Tano T: Avidobacterium capsulatum gen. nov. sp. nov.: an avidophilic chemoorganotrophic bacterium containing menaquinone from acidic mineral environment. Curr Mmicrobiol 1991 22:1-7.

30. Kuske CR, Barns SM, Busch JS: Diverse uncultivated bacterial groups from soils of the arid southwestern United States that are present in many geographic regions. Appl Environ Microbiol 1997, 63:3614-3621.

31. Rappe MS, Giovannoni SJ: The uncultured microbial majority. Annu Rev Microbiol 2003, 57:369-394.

32. Barns SM, Cain EC, Sommerville L, Kuske CR: Acidobacteria phylum sequences in uranium-contaminated subsurface sediments greatly expand the known diversity within the phylum. App/ Environ Microbio 2007, 73:3113-3116.

33. Wyrick P: Intracellular survival by Chlamydia. Cell Microbiol 2000, 2:275-282.

34. Dean D: Chlamydia trachomatis today: treatment, detection, immunogenetics and the need for a greater global understanding of chlamydial disease pathogenesis. Drugs Today (Barc) 2009, 45 Suppl B:25-31.

35. Skwor T, Kandel RP, Basravi S, Khan A, Sharma B, Dean D: Characterization of humoral immune responses to chlamydia HSP60, CPAF, and CT795 in inflammatory and severe trachoma. Invest Ophthalmol Vis Sci 2010, 51:5128-5136.
36. Takai T, Nakamura K, Toki T, Tsunogai U, Miyazaki M, Miyazaki J, Hirayama H, Nakagawa S, Nunoura T, Horikoshi K: Cell proliferation at $122^{\circ} \mathrm{C}$ and isotopically heavy $\mathrm{CH}_{4}$ production by a hyperthermophilic metanogen under high-pressure cultivation. Proc Natl Acad Sci 2008, 105:10949-10951.

37. Henry EA, Devereux R, Maki JS, Gilmour CC, Woese CR, Mandelco L, Schauder R, Remsen CC, Mitchell R: Characterization of a new thermophilic sulfate-reducing bacterium Thermodesulfovibrio yellowstonii, gen.nov. and sp.nov.: its phylogenetic relationship to Thermodesulfobacterium commune and their origins deep within the bacterial domain. Arch Microbiol 1994, 161:62-69.

38. Lien T, Madsen M, Rainey FA, Birkeland N-K: Petrotoga mobilis sp. nov., from a North Sea oil-production well. Int J Syst Bacteriol 1998, 48 pt 3:1007-1013.

39. Cayol J-L, Ollivier B, Patel BKC, Prensier G, Guezennec J, Garcia J-L: Isolation and characterization of Halothermothrix orenii gen. nov., sp. nov., a halophilic, thermophilic, fermentative, strictly anaerobic bacterium. Int J Syst Bacteriol 1994, 44:534-540.

40. Deckert G, Warren PV, Gaasterland T, Young WG, Lenox AL, Graham DE Overbeek R, Snead MA, Keller M, Aujay M, Huber R, Feldmand RA, Short JM, Olsen GJ, Swanson RV: The complete genome of the hyperthermophilic bacterium Aquifex aeolicus. Nature 1998, 392:353-358.

41. Ooteghem SAV, Beer SK, Yue PC: Hydrogen production by the thermophilic bacterium, Thermotoga neapolitana. Proceedings of the 200 DOE Hydrogen Program Review: NREL/CP-570-30535

42. Huang LN, Zhou H, Chen YQ, Luo S, Lan CY, Qu LH: Diversity and structure of the archaeal community in the leachate of a full-scale recirculating landfill as examined by direct $16 \mathrm{~S}$ rRNA gene sequence retrieval. FEMS Microbiol Lett 2002, 214:235-240.

43. Kendall MM, Liu Y, Sieprawska-Lupa M, Stetter KO, Whitman WB, Boone DR: Methanococcus aeolicus sp. Nov., a mesophilic, methanogenic aechaeon from shallow and deep marine sediments. Int J Syst Evol Microbiol 2006, 56:1525-1529.

44. Holt JG, Lewin RA: Herpetosiphon aurantiacus gen.et sp.n., a new filamentous sliding organism. J Bacteriol 1968, 95:2407-2408.

45. Jurkevitch E: Predatory behaviours in bacteria - diversity and transitions. Microb 2007, 2:67-73.

46. Sugio A, Kingdom HN, MacLean AM, Grieve VM, Hogenhout SA Phytoplasma protein effector SAP11 enhances insect vector reproduction by manipulating plant development and defense hormone biosynthesis. Proc Natl Acad Sci USA 2011, 108:E1254-E1263.

47. Nelson CE, Carlson CA: Tracking differential incorporation of dissolved organic carbon types among diverse lineages of Sargasso Sea bacterioplankton. Environ Microbiol 2012, 14:1500-1516.

48. Margassery LM, Kennedy J, O'Gara F, Dobson AD, Morrissey JP: Diversity and anti-bacterial activity of bacteria isolated from the coastal marine sponges Amphilectus fucorum and Eurypon major. Lett Appl Microbiol 2012, 55:2-8

49. Tian B, Hua Y: Carotenoid biosynthesis in extremophilic DeinococcusThermus bacteria. Trends Microbiol 2010, 18:512-520.

50. , Brachiopods information retrieved on 31 July 2012 [http://www.nmfs.noaa. gov/pr/species/invertebrates/\#brachiopods].

51. Lydeard $C$, Cowie RH, Ponder WF, Bogan AE, Bouchet P, Clark SA Cummings KS, Frest TJ, Gargominy O, Herbert DG, Hershler R, Perez KE, Roth B, Seddon M, Strong EE, Thompson FG: The global decline of nonmarine mollusks. BioScience 2004, 54:321-330.

52. Bugni TS, Ireland CM: Marine-derived fungi: a chemically and biologically diverse group of microorganisms. Nat Prod Rep 2004, 21:143-163.

53. Richards TA, Jones MDM, Leonard G, Bass D: Marine fungi: their ecology and molecular diversity. Ann Rev Mar Sci 2012, 4:495-522.

54. Singh $P$, Rathinasamy $K$, Mohan R, Panda D: Microtubule assemble dynamics: an attractive target for anticancer drugs. IUBMB Life 2008, 60:368-375.

55. Krajicek BJ, Thomas CF Jr, Limper AH: Pneumocystis pneumonia: current concepts in pathogenesis, diagnosis, and treatment. Clin Chest Med 2009, 30:265-278.

56. Laybourn-Parry JJ: Microbiology. No place too cold. Science 2009 324:1521-1522.

57. Patil SA, Surakasi VP, Koul S, limulwar S, Vivek A, Shouche YS, Kapadnis BP. Electricity generation using chocolate industry wastewater and its treatment in activated sludge based microbial fuel cell and analysis of developed microbial community in the anode chamber. Bioresour Technol 2009, 100:5132-5139. 
58. Fuerst JA, Sagulenko E: Beyond the bacterium: planctomycetes challenge our concepts of microbial structure and function. Nat Rev Microbiol 2011, 9:403-413.

59. Begum $D$, Murray J: Direct isolation of metagenomic DNA from environmental water samples. EPICENTRE forum 2008, 15:7-8.

60. Baker GC, Smith JJ, Cowan DA: Review and re-analysis of domain-specific $16 S$ primers. J Microbiol Methods 2003, 55:541-555.

61. Humblot C, Guyoet J-P: Pyrosequencing of tagged $16 \mathrm{~S}$ rRNA gene amplicons for rapid diciphering of the microbiomes of fermented foods such as pearl millet slurries. Appl Environ Microbiol 2009, 75:4354-4361.

62. Nossa CW, Oberdorf WE, Yang L, Aas JA, Paster BJ, DeSantis TZ, Brodie EL, Malamud D, Poles MA, Pei Z: Design of $16 \mathrm{~S}$ rRNA gene primers for 454 pyrosequencing of the human foregut microbiome. WJG 2010, 16:4135-4144

63. Meyer M, Stenzel U, Hofreiter M: Parallel tagged sequencing on the 454 platform. Nature Protocols 2008, 3:267-278.

64. Diez B, Pedros-Alio C, Massana R: Study of genetic diversity of eukaryotic picoplankton in different oceanic regions by small-subunit rRNA gene cloning and sequencing. Appl Environ Microbiol 2001, 67:2932-2941.

65. Grant S, Grant WD, Cowan DA, Jones BE, Ma Y, Ventosa A, Heaphy S: Identification of eukaryotic open reading frames in metagenomic CDNA libraries made from environmental samples. Appl Environ Microbiol 2006, 72:135-143.

66. Bailly J, Fraissinet-Tachet L, Verner M-C, Debaud J-C, Lemaire M, Wésolowski-Louvel M, Marmeisse R: Soil eukaryotic functional diversity, a metatranscriptomic approach. ISME J 2007, 1:632-642.

67. Altschul SF, Madden TL, Schäffer AA, Zhang J, Zhang Z, Miller W, Lipman DJ: Gapped BLAST and PSI-BLAST: a new generation of protein database search programs. Nucleic Acids Res 1997, 25:3389-3402.

68. Lagesen $\mathrm{K}$, Hallin P, Rødland EA, Staerfeldt HH, Rognese T, Ussery DW: RNAmmer: consistent and rapid annotation of ribosomal RNA genes. Nucleic Acids Res 2007, 35:3100-3108.

69. Katoh K, Toh H: Improved accuracy of multiple ncRNA alignment by incorporating structural information into a MAFFT-based framework. BMC Bioinformatics 2008, 9:212.

70. Kimura M: A simple method for estimating evolutionary rates of base substitutions through comparative studies of nucleotide sequences. J Mol Evol 1980, 16:111-120.

71. Felsenstein J: PHYLIP-phylogeny inference package (version 3.2). Cladistics 1989, 5:164-166.

72. Chao A, Chazdon RL, Colwell RK, Shen T-J: Abundance-based similarity indices and their estimation when there are unseen species in samples. Biometrics 2006, 62:361-371.

73. DeSantis TZ Jr, Hugenholtz P, Keller K, Brodie EL, Larsen N, Piceno YM, Phan R, Andersen GL: NAST: a multiple sequence alignment server for comparative analysis of 165 rRNA genes. Nucl Acids Res 2006, 34 : W394-W399.

doi:10.1186/1471-2164-13-S7-S29

Cite this article as: Somboonna et al: Metagenomic profiles of freeliving archaea, bacteria and small eukaryotes in coastal areas of Sichang island, Thailand. BMC Genomics 2012 13(Suppl 7):S29.

\section{Submit your next manuscript to BioMed Central and take full advantage of:}

- Convenient online submission

- Thorough peer review

- No space constraints or color figure charges

- Immediate publication on acceptance

- Inclusion in PubMed, CAS, Scopus and Google Scholar

- Research which is freely available for redistribution

Submit your manuscript at www.biomedcentral.com/submit
C Biomed Central 